\title{
The impact of community-based health promotion on quality of life: The need to control for general health trends. The Northern Sweden MONICA Study in 2014
}

Elin Spegel ( $\nabla$ elin.spegel@ltu.se )

Luleå univeristy of technology

Kristina Ek

Luleå university of technology

\section{Stefan Söderberg}

Umea Universitet Medicinska fakulteten

Mats Eliasson

Umea Universitet Medicinska fakulteten

\section{Research article}

Keywords: Prevention, promotion, health, QoL, VIP

Posted Date: April 15th, 2020

DOI: https://doi.org/10.21203/rs.2.18291/v2

License: (9) (1) This work is licensed under a Creative Commons Attribution 4.0 International License. Read Full License 


\section{Abstract}

Background: The Västerbotten Intervention Programme (VIP) is a public health promotion programme in northern Sweden aimed at preventing cardiovascular diseases. Its positive effects on disease risk factors and on the risk of coronary heart disease itself have been reported, although the evidence is not unequivocal. Since only historical controls have been used, effects from sources other than the programme have largely been uncontrolled for and health-related quality of life (QoL) has not been evaluated.

Methods: By using the neighbouring county of Norrbotten (NB) as a reference population, we compare QoL in Västerbotten (VB) and NB. In 2014, the World Health Organization's Monitoring of Trends and Determinants in Cardiovascular Disease (MONICA) Study was implemented in northern Sweden, where random samples from VB and NB were examined. In total, 1112 participants between the ages of 40 to 74 participated: 516 in VB, and 594 in NB. Their QoL was measured with the three-level EuroQol 5dimension (EQ-5D-3L) questionnaire. Differences in mean QoL between VB and NB were analysed via the Student's $t$-test and the Pearson chi-square test.

Results: Average QoL measured by the EQ-5D index was 0.798 in VB and 0.811 in NB, i.e. a difference of $0.013(p=0.2$; confidence interval/ $\mathrm{Cl}-0.009$ to 0.036). For participants aged 45-54, the QoL was lower in VB than in NB, showing a difference of 0.048 ( $p=0.041 ; \mathrm{Cl} 0.002$ to 0.0094). In NB, QoL decreased with age - a pattern not seen in VB. Men had higher QoL than women, and participants with a university education had higher QoL than those without one. The vertical visual analogue scale (EQ VAS) showed similar results. Participants from NB and from VB did not differ regarding age, gender or level of education.

Conclusions: We found similar levels of health-related QoL in VB and NB.

Trial registration: Not applicable

\section{Background}

Health problems due to lifestyle, such as obesity, unhealthy diets, a lack of physical activity and the use of tobacco and alcohol, are major causes of premature death in all high-income countries (1). In the early 1980s, the northern-most counties in Sweden, Västerbotten (VB) and Norrbotten (NB), reported the highest mortality rates from cardiovascular diseases in the country. Therefore, a community-based primary care intervention programme exercise known as the Västerbotten Intervention Programme (VIP) was launched in that county in the 1990's, with the aim of reducing morbidity and mortality not only from cardiovascular diseases, but diabetes as well (2).

Studies evaluating the effects of the VIP are inconclusive, however. For example, a report from 2015 draws relatively strong conclusions regarding reduced mortality from cardiovascular diseases (3), while a 2019 report found no evidence to support the claim that the VIP had contributed to any reduction of morbidity or mortality from cardiovascular diseases if one compared health trends in this regard in three of VB's neighbouring counties (4). Still others have evaluated the VIP's effects on intermediate health related outcomes. These studies report that certain lifestyle parameters have been enhanced by, among other things, a reduction in smoking (5), an increase in physical activity (6) and an improvement in self-reported health particularly among those whose initial state of health was poor or fair(7). In addition, a study of trends over time in respect of cardiovascular risk factors in VB, using the World Health Organization's Monitoring of Trends and Determinants in Cardiovascular Disease (MONICA) Study, showed a faster improvement in blood pressure and smoking but no difference in the prevalence of diabetes, cholesterol levels or BMI compared to the neighbouring county of NB (8).

However, many of these evaluations show a methodological limitation in that they fail to use a reference group. Thus, it is not possible to evaluate whether any effects are a result of the VIP or if they stem from other sources that are not controlled for, such as secular trends prevailing in Swedish society in general.

The purpose of this paper, therefore, is to evaluate whether there is a difference in quality of life (QoL) between VB and NB. Our hypothesis is that, after its implementation 20 years ago, the VIP should have had a health-promoting and disease-preventing 
effect in VB, and should thereby have led to a higher QoL for VB's population compared with that of its neighbours in NB. Moreover, since the population-based 2014 MONICA Study in northern Sweden was performed in both VB and NB, we were able to control for general health trends by using NB as the reference population, where VIP had not been implemented.

\section{Methods}

In this section a description of the intervention, the dataset including main variables and characteristics of the sample, and the statistical methods used to analyse the data, is given.

\section{Study setting}

The programme focuses on promoting health by offering counselling and support aimed at changing lifestyles to reduce morbidity and mortality from cardiovascular diseases and diabetes (see (2) for a full description of the VIP). The VIP is carried out in the primary health care in VB. The VIP was not implemented in NB.

Since 1990, all individuals aged 40, 50 or 60 living in VB have been encouraged to undergo a free health examination to measure body mass index, blood pressure, glucose tolerance and blood lipids, for example. The examinations include having all participants complete a comprehensive questionnaire on their lifestyle, socio-economic and psychosocial living conditions and general state of health, as well as receive health advice from a nurse. About 6000-7000 such examinations have been carried out in VB each year, distributed relatively evenly among the 40-, 50- and 60-year-old targets (9). The participation rate has varied, but it reveals an average of $63 \%$ of VB's population aged 40, 50 or 60 took part in the programme during the years 1990 to 2017 $(9,10)$.

Data

The World Health Organisation (WHO) MONICA was initiated as a multinational project with the purpose of monitoring trends and determinants in cardiovascular disease, it included repeated population-based surveys but no interventions. The Northern Sweden MONICA Study, which has been described in depth elsewhere (11)) focused on the country's two northernmost counties, VB and NB (Figure 1).

In brief, data for the MONICA Study are collected every four to five years by screening a subsample of the general population in respect of their health status, which includes screening for cardiovascular disease risk factors. Socio-demographic information about the participants is also collected during such exercises.

In the MONICA Study undertaken in northern Sweden in 2014 (12), the participants were also asked to rate their QoL. The invited participants were randomly selected yet stratified for gender into ten-year age cohorts, namely $25-34,35-44,45-54,55-64$, and 65-74. At each data collection point a total of 250 men and 250 women from each of the 5 age cohorts were invited to participate. Thus, 2500 invited participants from the two counties comprised the total 2014 study sample. The 2014 MONICA Study data used for the current research were restricted in that the age of 40 served as the lower cut-off. This allowed for comparisons with the VIP data, where participants were 40 years or older.

Telephone interviews with non-participants from previous MONICA surveys has shown that non-participants were not significantly different from participants in those surveys. For example, non-participants had somewhat lower body mass indices and were more likely to smoke, but they had achieved similar levels of education compared with participants (13).

Furthermore, to investigate the generalisability of the 2014 MONICA Study sample, we compared the VB and NB samples with their regional population averages with respect to age, gender and level of education. The results of these comparisons are presented in the section "Measurements". Regarding terminology, the notion regional population is defined here as those inhabitants residing within the geographical region of VB and NB in 2014.

\section{Measurements}




\section{Quality of life}

The five-dimension EuroQol (EQ-5D) is a well-established instrument used to describe and value health and consists of a standardised questionnaire developed by the EuroQol Group (14). The EQ-5D was therefore used to measure health-related QoL.

We used the three-level version of the questionnaire, namely the EQ-5D-3L, which comprises two parts. The first part involves five questions related to each of five dimensions of health: Mobility, Self-care, Usual activities, Pain/discomfort and Anxiety/depression. Each dimension in turn has three levels: No problems $=1$, Some problems $=2$, and Extreme problems $=3$. A participant is asked to indicate his/her health status by choosing the most appropriate level for each of the five dimensions. The digits for the five dimensions range from 1 to 3 and are combined into a five-digit number that describes a state of health, e.g. within the spectrum of 11111 to 33333 . The respondent's health can then be converted into a single index value (EQ-5D index) using a value set, ranging from 0 to 1 , where 0 represents a health state considered equal to death and 1 full health. The value set established by EQ-5D-based research for the United Kingdom was used in our study (15).

Part two of the EQ-5D-3L questionnaire consists of a visual analogue scale (EQ VAS), ranging from 0 to 100, where 0 represents the worst imaginable state of health and 100 represents the best imaginable. The respondent is asked to indicate his/her health status by drawing a line on the 0 to 100 scale. This VAS value can be used as a quantitative measure of QoL. The EQ-5D-3L is a widely used instrument for measuring QoL and has been shown to have good reliability and validity in the Swedish context (16).

\section{Terminology}

In the MONICA data, university education is defined as having completed an education at a college or university. In Sweden's national statistics, university education is defined as having completed a post-secondary education of three years or more, that is, being in possession of at least a Bachelor's degree.

\section{Characteristics of the sample}

In the age group 40-74, a total of 1110 of the 1750 invited to participate did so, namely by way of 516 respondents from VB and 594 from NB. This corresponds to a participation rate of $63 \%$.

In the 2014 MONICA Study sample, 35\% of all participants from VB had a university education, compared with $30 \%$ in NB; these percentages are higher than those for their respective regional populations (Table 1) (10). Moreover, $49 \%$ of respondents in VB and $53 \%$ in NB in the 2014 MONICA Study sample were women; the proportions in this regard are similar to those for the two respective regional populations (Table 1). And finally, in respect of the respondents' average age (57), Table 1 also shows it was similar not only for both counties that took part in the 2014 MONICA Study, but also for both counties' regional populations.

\section{Statistical methods}

Differences in mean QoL between VB and NB were analysed via the Student's $t$-test. Potential differences between VB and NB within the five dimensions of health were analysed via the Pearson chi-square test. Determinants of QoL were analysed in a multivariable linear regression model including age, gender and academic degree as explanatory variables. To test whether QoL differed between the counties, we performed two multivariable linear regression models - i.e. one with the EQ-5D index, and one with the EQ VAS - with QoL as the dependent variable and with an interaction term for VB and age. Application of the one-way analysis of variance (ANOVA) test and Welch's $t$-test (see Tables A3 and A4, respectively, in Appendix A) showed that pooling the two subsamples, VB and NB, was appropriate. The results are given with a 95\% confidence interval (Cl).

\section{Results}

\section{Health-related quality of life: The EQ-5D index and EQ VAS}

Page 4/14 
Participants from VB and NB report a mean EQ-5D index and EQ VAS of approximately 0.8 , with no significant differences between the two counties (Table 2).

The difference in the EQ-5D index between the counties was $0.01(p=0.2 ; \mathrm{Cl}-0.04$ to 0.01$)$, while the difference in the EQ VAS between them was $0.01(p=0.2 ; \mathrm{Cl}-0.03$ to 0.01$)$. There were no differences between the women from the two counties, on the one hand, nor between the men from those locations, on the other, with respect to both EQ-5D and EQ VAS (see Table A1 in Appendix A). However, a difference was recorded in the EQ-5D and EQ VAS between men and women in each respective county, in that women in both counties rated their QoL lower than that of their male counterparts (see Table A2 in Appendix A).

No differences in QoL were found between the counties according to the results of any of the models, namely the EQ-5D index $(p=0.13$; Cl 0.127 to -0.040$)$ and EQ VAS ( $p=0.11$; Cl 0.109 to -0.035$)$ (see Table A5 in Appendix A).

\section{Differences within the QoL dimensions}

Although we do not find any statistically significant difference in QoL between the counties as measured by the EQ-5D index or EQ VAS, we investigated whether there might be differences between the groups in respect of the five dimensions of health (Mobility, Self-care, Usual activities, Pain/discomfort and Anxiety/depression). Figure 2 presents the distribution of the responses for the three levels of each dimension of health for each county.

In both VB and NB, the dimensions Pain/discomfort and Anxiety/depression have a higher frequency of the ratings "some problems" and "extreme problems" than the other dimensions. We found no differences between the counties in any of the stated dimensions, as evidenced by $p$-values ranging from 0.1 to 0.4 (see Table B1 in Appendix B).

\section{Differences within age groups across counties}

We also analysed whether there were any differences between the two counties in terms of self-reported QoL in the various age groups. As Table 3 reveals, the EQ-5D index in the cohort aged 45-54 was lower in VB than in NB (see Table 3). No such pattern was found for the EQ VAS (see Table 4 and Table C1 in Appendix C).

Table 5 presents the results from the two multivariable linear regression models - one with the EQ-5D index and one with EQ VAS - which included an interaction term for VB and age.

The one-way ANOVA test (see Table C2 in Appendix C) shows that the variance related to QoL and age differs between the counties. The multivariable linear regression model (Table 5) shows that for the EQ-5D index the interaction term between VB and age implies that the effect of age on QoL differs between the counties. No such effect is found for EQ VAS.

\section{Discussion}

The purpose of this paper was to evaluate whether there were any differences in QoL between VB and NB, given that VB has had a community-based health-promoting programme since the 1990s, i.e. for over 20 years. The 2014 MONICA Study data collected in VB and NB offer a unique opportunity to use the participants from NB as a reference population to this end: VB and NB have similar socio-economic and demographic characteristics as well as a history of having the highest reported mortality rates from cardiovascular diseases in Sweden. The two counties also exhibit similar levels of living and working conditions, leisure and social life (17). In addition, the 2014 MONICA Study data make it possible to study potential differences in QoL between the counties from a societal perspective, rather than study the VIP's effect on individuals in the intervention group. In general, the impact of a public health promotion programme on a population - which is the purpose of the stated intervention in VB - depends not only on the effectiveness of the health-promoting activity itself, but also on the programme's ability to reach citizens and achieve long-lasting changes in lifestyle.

There are no large differences between participants from the two counties with respect to gender and age; nor do the VB and NB participants differ when compared with the regional averages for gender and age reported by Statistics Sweden (18).

Page 5/14 
Approximately one third of the participants from both VB and NB stated that they had a university degree; this was a substantially higher proportion than the relevant regional populations. Since education is positively related to QoL (19), there is a risk that the participants of the 2014 MONICA Study reported higher QoL than the general population. As explained in the terminology section earlier herein, the MONICA Study and Sweden's national statistics define university education differently. In the former, the term denotes having completed an education at a college or university, while in the latter it denotes having at least a Bachelor's degree. Hence, it is possible that the difference between the sample and the regional population stems at least to some extent from differences in how university education is defined. However, since the difference in educational attainment in comparison with the regional average is similar for both counties, and since we are interested in the difference between counties, the problems caused by selection bias is probably reduced in this context.

We found no significant differences in health-related QoL between the populations of VB (which had been subjected to the VIP) and NB (which had not). The only other research that compares VB with NB, that also uses the 2014 MONICA Study data, and that employs similar methods to those in this report, found a faster decline in blood pressure and smoking in VB when the two counties in question were compared, but found similar trends when the two were compared with respect to diabetes, cholesterol and obesity (8). However, the results of our study differ from a previous evaluation of the VIP's impact on self-reported health, which found the intervention had had a significant and positive effect in VB (7). One possible explanation for these contradicting results is that the previous evaluation of the VIP was based on the outcomes before and after the programme was implemented and did not compare the outcome with any reference population. In other words, they did not control for other factors that may have affected QoL over time, such as general societal trends affecting physical activity, education, diet and smoking habits, among other things. It should be noted that self-reported health is not the equivalent of QoL as measured by EQ-5D instruments.

Results from the multivariable linear regression models also show that men and the university-educated report higher QoL than women and those without such education. These results are consistent with findings in the literature (20-22).

Even though we do not find any evidence of differences in global QoL as measured by EQ-5D, it is reasonable to expect some of the EQ-5D dimensions to be more sensitive than others to changes in lifestyle. For example, the positive effects of physical exercise on anxiety and depression as well as on pain are well documented in the literature $(23,24)$, and since the VIP promotes physical exercise, a higher share of reported "No problems" in the VB sample could be expected within these dimensions if the programme has succeeded in increasing physical activity in the VB population. However, no differences between the two counties were found within any of the EQ-5D dimensions.

In addition, we tested whether there were any differences in QoL for different age groups in the two counties. It would be reasonable to expect the VIP's effect on QoL to increase with age: its aim is to prevent future illnesses, and its impact on QoL should presumably be more visible as age increases. In addition, since all individuals aged 40,50 or 60 in VB are invited to the health examinations, those who are older have had the opportunity of participating in the VIP on more than one occasion, which may also increase the probability of their lifestyles having improved. Nonetheless, we only found a difference for the EQ-5D index between the counties in one of four age groups, namely those aged 45 to 54 . Our study shows that it was in fact participants in NB who had a higher QoL than participants in their age cohort in VB. Thus, we do not find any evidence that global QoL is higher in VB - not only within any EQ-5D dimension, but also not within any specific age group.

Although the results do not support the VIP having improved QoL in VB, our results show that, despite younger participants from VB having a lower QoL, the QoL is not decreasing with increasing age in the VB sample - unlike in the NB sample. Based on the findings in previous studies, in Sweden and elsewhere, health status has generally been found to decrease with age $(25,26)$. The difference found between the counties regarding the relationship between QoL and age could be an indication that the VIP has had some positive effect on QoL.

\section{Policy implications}


To break the trend with increasing lifestyle-related morbidity and mortality, population based preventative measures are needed. In addition, to make resource-efficient decisions, policymakers need information about the outcomes as well as the costs of the measures available. The main contribution of this study, therefore, lies in pointing at the importance of controlling for changes in QoL stemming from sources other than the VIP, namely by comparing the population of the intervention area with a similar reference group. However, for broad population-based programmes, suitable reference groups are often not available (28); as a result, the effect of such programmes may be over- or undervalued. In such cases, it is important for policymakers to be aware of the validity issues stemming from not controlling for possible changes over time in general health trends or lifestyle.

\section{Limitations}

One limitation of this study is that we only have one point of measure for the QoL. If data over QoL from multiple points over time had been available, it would have been possible to account for any starting point differences between the intervention and control groups. Since future MONICA Study surveys will collect such data, this will be an important avenue for future research.

Another limitation is that we are unable to control for possible differences between the share of individuals in the 2014 MONICA Study data that took part in the VIP, on the one hand, and the share of VIP participants in the VB population at large, on the other. The 63\% participation rate for the 2014 MONICA Study was similar in the two counties; although this rate is not significantly different from participation levels in MONICA Study surveys in previous years, a relatively high proportion of nonparticipants constitutes a risk of selection bias. Nonetheless, the subsample from the general population invited to participate in the 2014 MONICA Study was randomly selected, and has been shown to adequately represent the general population with regard to sociodemographic aspects (13).

In addition, although the EQ-5D-3L is found to perform well for many health conditions, there are studies that have questioned the instrument's ability to accurately capture the QoL of the general population $(19,27)$. According to the findings of these studies, EQ-5D-3L's ability to capture QoL varies by dimension. For example, the domains Self-care and Usual activities did not help to explain the QoL significantly in the general population in those studies. However, adding more dimensions such as Concentration, Sleep and Sexual activity only resulted in small improvements in explaining individual differences in QoL. Hence, although the EQ-5D-3L could potentially be improved, by increasing the number of response levels, the overall conclusion in the literature is that the widely used EQ-5D-3L is a valid instrument for measuring QoL in the general population.

Another limitation of the study is the potential of the VIP's spillover effects on NB's (and the rest of Sweden's) population. Finally, the risk of spurious results due to mass comparisons should be noted; in the current study, this entailed the difference found in a single age group within eight comparisons.

\section{Conclusions}

We do not find any difference in QoL between VB and its neighbouring county NB, despite the population in VB having been exposed to a public health promotion programme for over 20 years. However, even though no difference is found between the samples on average, the QoL in the VB sample did not decrease with age - unlike what is commonly found in other studies and in the reference population in NB. Thus, it cannot be ruled out that this lack of declining health with age in Västerbotten is a result of the preventative focus of that county's health intervention programme, together with a repetitive exposure for older participants.

\section{Declarations}

\section{Ethics approval and consent to participate}

The present study was approved by the Regional Ethics Committee at Umeå University (Umeå, Sweden) 2013, dnr 2013/97-21.

\section{Consent for publication}

Page $7 / 14$ 


\section{Availability of data and materials}

The data that support the findings of this study are available on request from the Biobank Research Unit at Umeå University, Umeå, Sweden, after ethics approval by the Regional Ethics Committee at Umeå University, Umeå, Sweden. The data are not publicly available due to the data set containing information that could compromise the participants' privacy.

\section{Competing interests}

The authors declare that they have no competing interests.

\section{Funding}

The authors disclose receipt of financial support from the Norrbotten County Council for the research, authorship and publication of this article. The funders played no role in the design of the study; the collection, analysis or interpretation of the data; or in writing the manuscript.

\section{Authors' contributions}

ME contributed to the idea for the paper and the conception and design of the data material. ES contributed by way of the statistical analysis. ES and KE's contributions constituted interpretation of data for the work as well as the drafting of the manuscript. SS contributed in respect of supplying the data as principal investigator of the MONICA Study in northern Sweden and was involved in the interpretation of the data. All authors critically revised the manuscript, gave final approval, and agree to be accountable for all aspects of work ensuring integrity and accuracy.

\section{Acknowledgements}

We would like to acknowledge Robert Lundqvist, statistician at the Norrbotten County Council, for his advice regarding statistical analysis and technical support regarding the statistical software.

\section{Authors' information}

Elin Spegel is a postdoctoral researcher in Health Economics at the Luleå University of Technology. Her research area is environmental and health economics.

Kristina Ek is an Associate Professor of Economics at the Luleå University of Technology. Her research area is environmental and health economics.

Mats Eliasson is an Adjunct Professor at the Department of Public Health and Clinical Medicine, Umeå University. His research area is cardiovascular risk factors, including diabetes as a risk factor for myocardial infarction and stroke. He has also done research on quality of life and its relationship to lifestyle and socio-economic factors.

Stefan Söderberg is a Professor of Internal Medicine and a Senior Consultant in Cardiology at the Department of Public Health and Clinical Medicine, Umeå University. His research area is cardiovascular epidemiology nationally and internationally. Stefan Söderberg is also the principal investigator for the MONICA Study in northern Sweden.

\section{Abbreviations}


$\mathrm{Cl}$ - confidence interval

EQ-5D - A EuroQol questionnaire investigating five dimensions of health

EQ-5D-3L - A EuroQol questionnaire investigating five dimensions of health according to three levels of responses

EQ-5D index - A single index made up by the EuroQol 5 dimensions of health

EQ VAS - A visual analogue scale used in the EQ-5D questionnaire for respondents to self-rate their health

MONICA - Monitoring of Trends and Determinants in Cardiovascular Disease

NB - Norrbotten County

QoL - health-related quality of life

VB - Västerbotten County

VIP - Västerbotten Intervention Programme

WHO - World Health Organization

\section{References}

(1) World Health Organization. Global Health Estimates 2016: Deaths by Cause, Age, Sex, by Country and by Region, $2000-2016$. 2017; Available at: https://www.who.int/healthinfo/global_burden_disease/estimates/en/. Accessed 11/20, 2018.

(2) Norberg M, Wall S, Boman K, Weinehall L. The Västerbotten Intervention Programme: background, design and implications. Global Health Action 2010 12/01;3(1):4643.

(3) Blomstedt Y, Norberg M, Stenlund H, Nyström L, Lönnberg G, Boman K, et al. Impact of a combined community and primary care prevention strategy on all-cause and cardiovascular mortality: a cohort analysis based on 1 million person-years of followup in Västerbotten County, Sweden, during 1990-2006. BMJ Open 2015 12/01;5(12):e009651.

(4) San Sebastián M, Mosquera PA, Gustafsson PE. Do cardiovascular disease prevention programs in northern Sweden impact on population health? An interrupted time series analysis. BMC Public Health 2019 02/15;19(1):202.

(5) Norberg M, Lundqvist G, Nilsson M, Gilljam H, Weinehall L. Changing patterns of tobacco use in a middle-aged population the role of snus, gender, age, and education. Global Health Action 2011 12/01;4(1):5613.

(6) Ng N, Söderman K, Norberg M, Öhman A. Increasing physical activity, but persisting social gaps among middle-aged people: trends in Northern Sweden from 1990 to 2007. Global Health Action 2011 12/01;4(1):6347.

(7) Blomstedt Y, Emmelin M, Weinehall L. What about healthy participants? The improvement and deterioration of self-reported health at a 10-year follow-up of the Västerbotten Intervention Programme. Global Health Action 2011 12/01;4(1):5435.

(8) Eliasson M, Eriksson M, Lundqvist R, Wennberg P, Söderberg S. Comparison of trends in cardiovascular risk factors between two regions with and without a community and primary care prevention programme. Eur J Prev Cardiolog 2018 11/01; 2019/06;25(16):1765-1772.

(9) Lönnberg G. VHU 1990-2017 - deltagande. 2018; Available at:

https://public.tableau.com/profile/epiglobe\#!/vizhome/VHU1990-2014/Adderatdeltagande. (Accessed: 2018-10-12). Accessed 10/12, 2018. 
(10) Statistics Sweden. Folkmängd efter region, ålder och år. 2018; Available at:

http://www.statistikdatabasen.scb.se/pxweb/sv/ssd/START_BE_BE0101_BE0101A/BefolkningNy/table/tableViewLayout1/? rxid=3b7dd43b-3af2-4d9f-9e81-258998b92664. Accessed 10/22, 2018.

(11) Stegmayr B, Lundberg V, Asplund K. The events registration and survey procedures in the Northern Sweden MONICA Project. Scand J Public Health 2003 11/01; 2019/06;31(61):9-17.

(12) Eriksson M, Forslund A, Jansson J, Söderberg S, Wennberg M, Eliasson M. Greater decreases in cholesterol levels among individuals with high cardiovascular risk than among the general population: the northern Sweden MONICA study 1994 to 2014. Eur Heart J 2016 07/01;37(25):1985-1992.

(13) Eriksson M, Stegmayr B, Lundberg V. MONICA quality assessments. Scand J Public Health 2003 11/01; 2019/06;31(61):2530.

(14) EuroQol. EuroQol - a new facility for the measurement of health-related quality of life. Health Policy 1990 December 1990;16(3):199-208.

(15) Dolan P. Modeling Valuations for EuroQol Health States. Med Care 1997;35(11).

(16) Burström K, Sun S, Gerdtham U, Henriksson M, Johannesson M, Levin L, et al. Swedish experience-based value sets for EQ5D health states. Quality of Life Research 2014 03/01;23(2):431-442.

(17) Tillväxtverket. Hållbar utveckling i svenska regioner? 2018 2018;0251.

(18) Statistics Sweden. Befolkning efter region, ålder, utbildning och år. 2018; Available at: 22. Accessed 10, 2018.

(19) Janssen MF(, Birnie E, Bonsel GJ. Evaluating the discriminatory power of EQ-5D, HUI2 and HUI3 in a US general population survey using Shannon's indices. Quality of Life Research 2007 06/01;16(5):895-904.

(20) Szende A, Janssen B. Socio-demographic indicators Based on EQ-5D. In: Szende A, Janssen B, Cabases J, editors. SelfReported Population health: An International Perspective based on EQ-5D Dordrecht: Springer; 2014.

(21) Bisegger C, Cloetta B, von Bisegger U, Abel T, Ravens-Sieberer U, the European Kg. Health-related quality of life: gender differences in childhood and adolescence. Sozial- und Präventivmedizin 2005 10/01;50(5):281-291.

(22) Moor I, Günther S, Knöchelmann A, Hoebel J, Pförtner T, Lampert T, et al. Educational inequalities in subjective health in Germany from 1994 to 2014: a trend analysis using the German Socio-Economic Panel study (GSOEP). BMJ Open 2018 06/01;8(6):e019755.

(23) Ströhle A. Physical activity, exercise, depression and anxiety disorders. J Neural Transm 2008 08/23;116(6):777.

(24) Chekroud SR, Gueorguieva R, Zheutlin AB, Paulus M, Krumholz HM, Krystal JH, et al. Association between physical exercise and mental health in 1.2 million individuals in the USA between 2011 and 2015: a cross-sectional study. The Lancet Psychiatry 2018 September 2018;5(9):739-746.

(25) Janssen MF, Pickard AS, Golicki D, Gudex C, Niewada M, Scalone L, et al. Measurement properties of the EQ-5D-5L compared to the EQ-5D-3L across eight patient groups: a multi-country study. Quality of Life Research 2013 09/01;22(7):17171727.

(26) Robert SA, Cherepanov D, Palta M, Dunham NC, Feeny D, Fryback DG. Socioeconomic Status and Age Variations in HealthRelated Quality of Life: Results From the National Health Measurement Study. psychsocgerontology 2009;64B(3):378-389.

(27) Jelsma J, Maart S. Should additional domains be added to the EQ-5D health-related quality of life instrument for community-based studies? An analytical descriptive study. Population Health Metrics 2015 06/02;13(1):13.

Page $10 / 14$ 
(28) Drummond MF, Schulpher MJ, Claxton K, Stoddart GL, Torrance GW. Methods for the Economic Evaluation of Health Care Programmes. Oxford: Oxford University Press; 2015.

\section{Tables}

Table 1. Sample characteristics in comparison with the regional population

\begin{tabular}{llcc}
\hline \multirow{2}{*}{ Variable } & County & 2014 MONICA Study participants & Regional population age group: 40-74 \\
\cline { 3 - 5 } & & Mean & Mean \\
\hline University education (\%) & Västerbotten & 35 & 19 \\
& Norrbotten & 30 & 50 \\
\hline Proportion women (\%) & Västerbotten & 49 & 49 \\
\hline Average age (y) & Norrbotten & 53 & 57 \\
\hline
\end{tabular}

Table 2. QoL by EQ-5D index and EQ VAS stratified by gender and county

\begin{tabular}{|c|c|c|c|c|}
\hline Variable & County & Mean & Standard deviation & $\begin{array}{c}p \text {-value difference of means; } \\
\text { confidence interval }\end{array}$ \\
\hline \multicolumn{5}{|c|}{ EQ-5D index } \\
\hline \multirow[t]{2}{*}{ Average } & Västerbotten & 0.80 & 0.19 & $0.2 ;-0.04$ to 0.01 \\
\hline & Norrbotten & 0.81 & 0.19 & \\
\hline \multirow[t]{2}{*}{ Men } & Västerbotten & 0.82 & 0.17 & $0.1 ;-0.05$ to 0.06 \\
\hline & Norrbotten & 0.85 & 0.16 & \\
\hline \multirow[t]{2}{*}{ Women } & Västerbotten & 0.77 & 0.21 & $0.6 ;-0.04$ to 0.02 \\
\hline & Norrbotten & 0.78 & 0.21 & \\
\hline \multicolumn{5}{|l|}{ EQ VAS } \\
\hline \multirow[t]{2}{*}{ Average } & Västerbotten & 0.79 & 0.16 & $0.2 ;-0.03$ to 0.01 \\
\hline & Norrbotten & 0.80 & 0.17 & \\
\hline \multirow[t]{2}{*}{ Men } & Västerbotten & 0.81 & 0.15 & $0.1 ;-0.05$ to 0.01 \\
\hline & Norrbotten & 0.83 & 0.15 & \\
\hline \multirow[t]{2}{*}{ Women } & Västerbotten & 0.76 & 0.17 & $0.6 ;-0.04$ to 0.05 \\
\hline & Norrbotten & 0.77 & 0.17 & \\
\hline
\end{tabular}

Table 3. EQ-5D index by age group and county 


\begin{tabular}{cccccc}
\hline Age group & County & $\mathrm{N}$ & Mean & Standard deviation & $p$-value difference of means; confidence interval \\
\hline \multirow{2}{*}{$40-44$} & Västerbotten & 70 & 0.81 & 0.19 & $0.1 ;-0.10$ to 0.01 \\
& Norrbotten & 65 & 0.85 & 0.12 & $0.04 ;-0.09$ to -0.00 \\
\hline $45-54$ & Västerbotten & 143 & 0.78 & 0.23 & $0.7 ;-0.04$ to 0.05 \\
& Norrbotten & 176 & 0.83 & 0.17 & 0.19 \\
\hline $55-64$ & Västerbotten & 151 & 0.80 & 0.22 & $0.7 ;-0.03$ to 0.05 \\
& Norrbotten & 189 & 0.79 & 0.15 & 0.20 \\
\hline
\end{tabular}

Table 4. EQ VAS by age group and county

\begin{tabular}{cccccc}
\hline Age group & County & $\mathrm{N}$ & Mean & Standard deviation & $p$-value difference of means; confidence interval \\
\hline \multirow{2}{*}{$40-44$} & Västerbotten & 70 & 0.79 & 0.16 & $0.2 ;-0.08$ to 0.02 \\
& Norrbotten & 65 & 0.83 & 0.13 & $0.08 ;-0.07$ to -0.00 \\
\hline \multirow{2}{*}{$45-54$} & Västerbotten & 143 & 0.78 & 0.18 & $0.2 ;-0.03$ to 0.04 \\
& Norrbotten & 176 & 0.81 & 0.15 & $1.0 ;-0.04$ to 0.03 \\
\hline $55-64$ & Västerbotten & 151 & 0.78 & 0.16 & 0.18 \\
& Norrbotten & 189 & 0.78 & 0.14 & 0.17 \\
\hline
\end{tabular}

Table 5. Multivariable linear regression model with an interaction term for Västerbotten County and age 


\begin{tabular}{l|lcccccc}
\hline Dependent variable & Independent variables & Coefficient & Standard error & P-value & $t$ & & 95\% confidence interval \\
& & & & & & & \\
& & & & & Lower bound & Upper bound \\
\hline EQ-5D index & Intercept & 0.915 & 0.048 & 0.000 & 18.995 & 0.820 & 1.009 \\
& No univ. educ. & -0.055 & 0.012 & 0.000 & -4.487 & -0.079 & -0.031 \\
& Västerbotten & -0.161 & 0.069 & 0.020 & -2.336 & -0.296 & -0.026 \\
& Men & 0.064 & 0.011 & 0.000 & 5.569 & 0.041 & 0.086 \\
& Age & -0.002 & 0.001 & 0.045 & -2.010 & -0.003 & 0.00 \\
& Västerbotten*age & 0.003 & 0.001 & 0.035 & 2.113 & 0.000 & 0.005 \\
\hline \multirow{2}{*}{ EQ VAS } & Intercept & 0.882 & 0.041 & 0.000 & 21.382 & 0.801 & 0.962 \\
& No univ. educ. & -0.047 & 0.011 & 0.000 & -4.419 & -0.067 & -0.026 \\
& Västerbotten & -0.114 & 0.059 & 0.054 & -1.931 & -0.230 & 0.002 \\
& Men & 0.056 & 0.010 & 0.000 & 5.734 & 0.037 & 0.075 \\
& Age & -0.001 & 0.001 & 0.056 & -1.915 & -0.003 & 0.000 \\
& Västerbotten*age & 0.002 & 0.001 & 0.091 & 1.689 & 0.000 & 0.004 \\
\hline
\end{tabular}

\section{Figures}

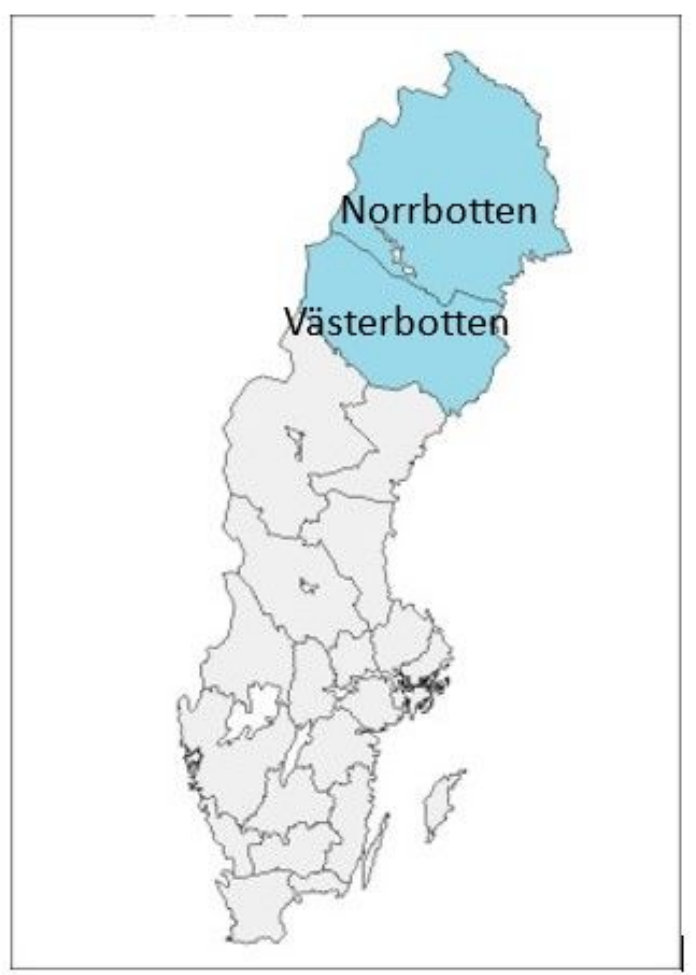

Figure 1 
Geographical map of the counties Norrbotten and Västerbotten, Sweden.

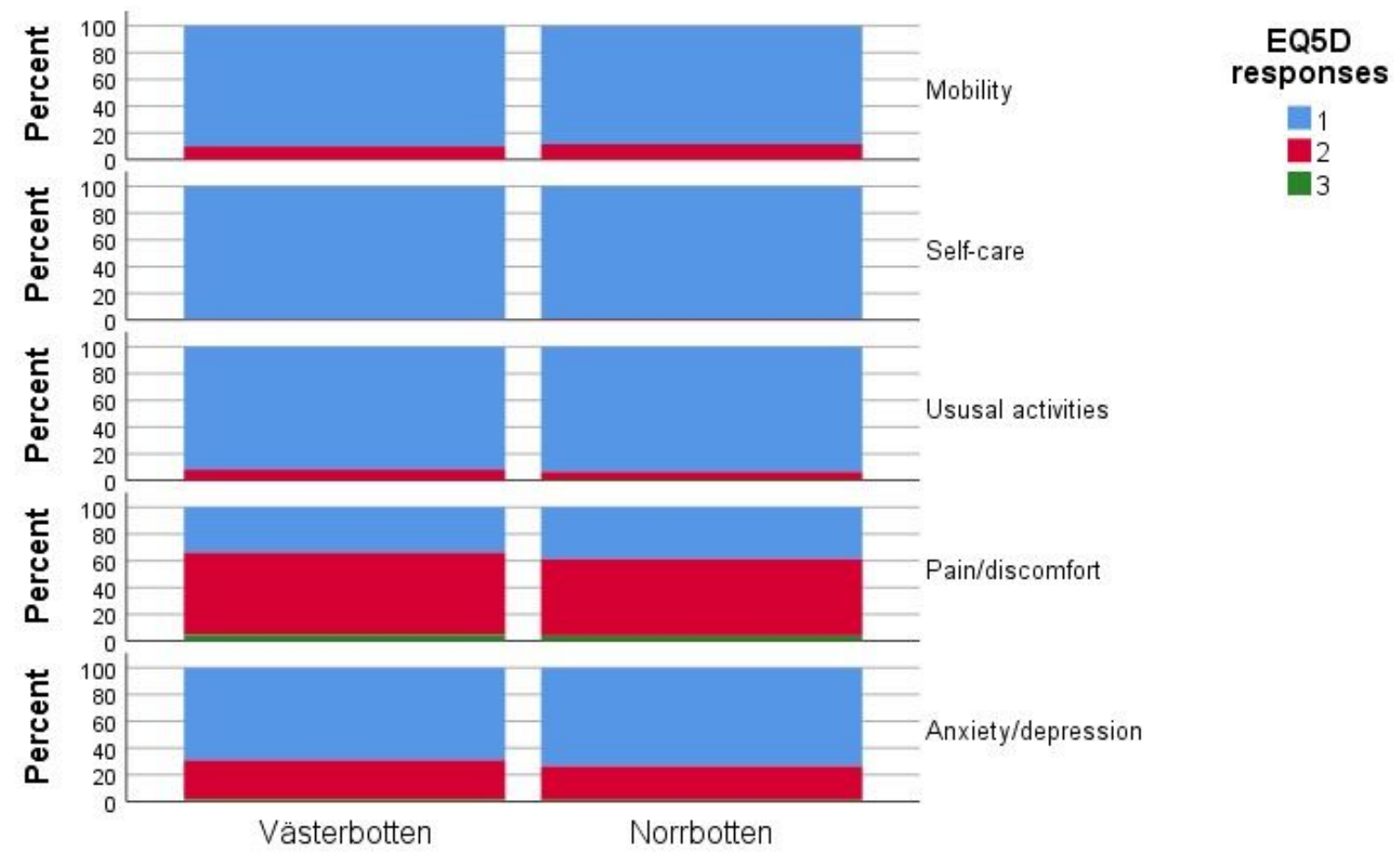

\section{Figure 2}

Distribution of responses to the EQ-5D questionnaire (No problems $=1$, Some problems $=2$, Extreme problems $=3$ ), by county

\section{Supplementary Files}

This is a list of supplementary files associated with this preprint. Click to download.

- Appendices.docx 